\title{
¿Es posible la filosofía de la religión en la época moderna a través del pensamiento de Kant y Schleiermacher?
}

\author{
Does the philosophy of religion in modern times is possible \\ through the thought of Kant and Schleiermacher?
}

JOSÉ MORALES FABERO*

\begin{abstract}
Resumen: Con el movimiento de la ilustración, Kant llamaba a hacer uso público de una razón mayor de edad para desmontar el pensamiento dogmático de los tutores y abrirse a formas de argumentación libres y emancipadoras. Por otro lado, es sabido cómo el romanticismo surge como reacción frente al pensamiento ilustrado. El espíritu de la época busca refugio en el sentimiento después de la pérdida del contenido absoluto. Esta nueva figura -el sentimiento- va a ser a los ojos de Hegel la conclusión lógica a que ha conducido la Ilustración. Aquí va a residir el motivo fundamental del enfrentamiento entre la Ilustración y el Romanticismo, donde las figuras de Kant y Schleiermacher se encuentran o quizás se separan en cuanto al ámbito que debe corresponder a la filosofía, a la religión y si hay un punto de encuentro en las dos (Filosofía de la Religión).

Palabras clave: Filosofía, Religión, Filosofía de la Religión, Ilustración, Romanticismo y Época Moderna.
\end{abstract}

\begin{abstract}
With the movement of the Enlightenment, Kant called to make public use of one major reason to disassemble the dogmatic thinking of tutors and open up to free and emancipatory forms of argumentation. On the other hand, know how romanticism emerges as a reaction to the enlightened thinking. The spirit of the times seeks refuge in sentiment after the loss of the absolute content. This new figure -the feeling- is going to be the logical conclusion that has led the illustration in the eyes of Hegel. Here's to reside the fundamental motive of the confrontation between the enlightenment and romanticism, where Kant and Schleiermacher figures are or maybe are separated in the field which should correspond to philosophy, religion and if there is a meeting point in the two (philosophy of Religion).

Keywords: Philosophy, Religion, philosophy of Religion, enlightenment, romanticism and modern times.
\end{abstract}

\section{Introducción}

Si la filosofía antigua había tomado la realidad objetiva como punto de partida de su reflexión filosófica, y la medieval había tomado a Dios como referencia, la filosofía moderna se asentará en el terreno de la subjetividad. Las dudas planteadas sobre la posibilidad de un

Fecha de recepción: 24/01/2015. Fecha de aceptación: 30/04/2015.

* Diplomado en Trabajo Social, Licenciado en Humanidades, Máster en Filosofía Teórica y Práctica por la UNED. Actualmente trabaja en la tesis doctoral sobre "El autoritarismo en la modernidad: una reflexión de Richard Rorty y Boaventura de Sousa", bajo la tutela del Dr. Jacinto Rivera de Rosales Chacón. Publicaciones disponibles en: https://www.researchgate.net/profile/Jose_Morales_Fabero/stats. E-mail: jmoralesf@hotmail.es. 
conocimiento objetivo de la realidad, material o divina, harán del problema del conocimiento el punto de partida de la reflexión filosófica. Son muchos los acontecimientos que tienen lugar al final de la Edad Media, tanto de tipo social y político, como culturales y filosóficos, que abrirán las puertas a la modernidad, y que han sido profusamente estudiados. En lo filosófico, el desarrollo del humanismo y de la filosofía renacentista, junto con la revolución copernicana, asociada al desarrollo de la Nueva Ciencia, provocarán el derrumbe de una Escolástica ya en crisis e impondrán nuevos esquemas conceptuales, alejados de las viejas e infructuosas disputas terminológicas que solían dirimirse a la luz de algún argumento de autoridad, fuera platónica o aristotélica.

Cómo es de sobra sabido, la Filosofía Moderna comienza en el Renacimiento y la Reforma Protestante. Es a René Descartes a quien se le considera como el padre de ésta. Él exigió para el pensar filosófico una absoluta autonomía de modo que vinieron a desarticularse la razón y la fe. Se entroniza la Razón y el antropocentrismo como ejes vertebradores y configuradores del hombre moderno que tiene su correlato en la Revolución Francesa y los Ilustrados, y que da cuerpo, como sistema filosófico, Immanuel Kant.

Detrás de la pérdida de los dioses subyace el gran interrogante ontológico de los siglos XIX y XX: ¿Qué es la vida?, ¿Cuál es la verdadera vida, qué significa vivir verdaderamente o qué es vivir según un querer vivir? La experiencia de la modernidad ha significado que el hombre se encuentra enteramente a solas en el escenario existencial que habita. La más intensa potencia tecnológica expresiva de nuestra cultura moderna deja al hombre contemporáneo en una situación de indigencia, de pobreza ante el arraigo, la solidez y los sentidos de la vida. Como es sabido, Heidegger señala, como una de las manifestaciones de la Edad Moderna, la desdivinización. Sin embargo, esta "desdivinización” no supone, sin más, la eliminación de la religiosidad, sino que más bien "a través de ella, la referencia a los dioses se transforma en la experiencia religiosa. Al llegar a este punto, se desvanecen los dioses. El vacío así surgido es rellenado por la investigación histórica y psicológica" (Heidergger, 2010, págs. 63-79). Es justo afirmar que Schleiermacher expresa con claridad la situación descrita por Heidegger, pues, no vacilaba en afirmar que los pensamientos especulativos más profundos vienen a identificarse para él con sus sentimientos más íntimos. En concreto, en lo referente a la interpretación del ámbito teológico y religioso salta a la vista la intensidad con que Schleiermacher recurre a la psicología para exponer su punto de vista.

Tras las guerras de religión que cubren la Europa del siglo XVII, la religión que había impuesto la razón rectora, que antes unía a los pueblos, ahora separa. Así Europa pierde la base de sustentación sobre la que descansaba su identidad y que legitimaba el viejo orden social. Nos encontramos en un momento histórico en el que precisamente está tomando auge esa nueva disciplina que pronto va a ser conocida con el nombre de "filosofía de la religión". El problema de la religión aparece, en efecto, con frecuencia dentro de la filosofía de esta época, tanto en Kant, Hegel y Schleiermacher. Estamos, por tanto, ante un concepto clave de este momento histórico que remite a una nueva situación respecto del fenómeno religioso (Fraijó, 2010, 13-42).

En la época moderna la filosofía alcanza un ámbito nuevo al ser examinada la religión a través del pensamiento racional. Ello fue posible, en buena medida debido a la crítica de la Ilustración a la tradición teológica, que le permitió abocar más bien en un concepto neutro de religión - la religión natural- como único fundamento válido, que subyacía a los distintos 
fenómenos religiosos. Junto con todo ello aparecía asimismo un nuevo clima de tolerancia religiosa, que tanto obsesionó a los ilustrados y una nueva conciencia de la autonomía de la moral que tan profundamente vivió Kant. Precisamente, con la llegada del Renacimiento y la Modernidad, tuvo lugar el cuestionamiento del pensamiento dogmático:

El nacimiento de la filosofía de la religión fue posible por la demolición de muchos absolutos, religiosos, morales, culturales, sociales y políticos. Como consecuencia de los descubrimientos de nuevas religiones (...) se ensancharon los horizontes mentales europeos y se relativizaron el cristianismo y su moral... Con la Modernidad llegó la investigación histórico-crítica de los textos y la Biblia dejó de ser un conjunto claro y coherente de libros: se descubrió que en las páginas sagradas había errores, contradicciones e intereses humanos. Cuando Lessing publicó los fragmentos de Hermann Samuel Reimarus en los que éste afirmaba que Jesús fue un mesías político fracasado y que fueron sus discípulos los que lo convirtieron en un mesías espiritual, comenzó a ponerse de relieve que el texto sagrado era susceptible de variadas interpretaciones. (Fraijó, 2010, 28-29).

Estos y otros hechos fueron la condición indispensable para que naciera la filosofía de la religión, que propugna una reflexión libre y objetiva sobre el hecho religioso. Resquebrajadas las servidumbres confesionales y dogmáticas, la filosofía de la religión nació con una decidida vocación emancipatoria. Se atrevió a seguir el consejo del opúsculo ¿Qué es Ilustración?, en el que Kant llamaba a hacer uso público de una razón mayor de edad para desmontar el pensamiento dogmático de los tutores y abrirse a formas de argumentación libres y emancipadoras: “ ¡Sapere aude! ¡Ten el valor de servirte de tu propia razón! He aquí el lema de la Ilustración" (Kant, 2004, 83). Por otro lado, es sabido cómo el romanticismo surge como reacción frente al pensamiento ilustrado. El espíritu de la época busca refugio en el sentimiento después de la pérdida del contenido absoluto. Esta nueva figura -el sentimiento- va a ser a los ojos de Hegel la conclusión lógica a que ha conducido la Ilustración: "en el intento de escapar a la obra secularizadora de la Ilustración se trata de buscar refugio en el sentimiento". Aquí va a residir el motivo fundamental del enfrentamiento entre la Ilustración y el Romanticismo, donde las figuras de Kant y Schleiermacher se encuentran o quizás se separan en cuanto al ámbito que debe corresponder a la filosofía, a la religión y si hay un punto de encuentro en las dos.

Juntas nacieron sin duda la filosofía y la teología en el alba del pensamiento; si luego fue necesario separarlas porque su unión se había pervertido en kantiana "lucha de facultades" o en doméstica rivalidad de sierva y señora, tal vez llegó el momento de una unión dialogal e igualitaria, como tantas cosas. Hegel lo había dicho ya a su modo en la introducción a sus Lecciones sobre la historia de la filosofía:

1 Georg Wilhelm Friedrich Hegel. "Vorlesungen über, die Philosophie der Religion”, I, i, F Meiner, Hamburgo, 1966, p. 5. "A lo largo de la Edad Moderna se ha ido ensanchando cada vez más el conocimiento de lo finito mientras que, por el contrario, el conocimiento de la Divinidad se ha ido haciendo cada vez más impreciso. Por supuesto que el espíritu debe ocuparse de lo finito, de lo terreno, pero existe una necesidad superior de que el hombre tenga un "domingo de la vida" en el que se levante por encima de las necesidades de la vida cotidiana y se ocupe de lo Verdadero sin más” Hegel $(1966,5)$. 
La historia de la Filosofía despliega ante nosotros la sucesión de los espíritus nobles, la galería de los héroes de la razón pensante, que, sostenidos por la fuerza de esta razón, han sabido penetrar en la esencia de las cosas, de la Naturaleza y del espíritu, en la esencia de Dios, y que han ido acumulando con su esfuerzo, para nosotros, el más grande de los tesoros: el del conocimiento racional. (Hegel, 1995, 8).

Por otro lado, existe también una esperanza del hombre puesta en la religión, cuando sus necesidades no le han sido cubiertas en este mundo, o cuando se siente indefenso a merced del cosmos, e incluso cuando se siente el hombre con una pérdida de seguridad, y por ende añora a un padre, cuya nueva forma es la de "un padre celestial". Para Freud, la religión es una facultad imaginativa del hombre que le ha permitido superar sus angustias, creando ilusiones con "futuro". Es por lo anterior que la religión puede ser concebida como un sistema de interpretaciones y explicaciones pre-racionales. La religión sin embargo ha hecho frente a las exigencias, por un lado de la ciencia en cuanto a sus reclamos prácticos y a los teóricos por parte de la filosofía, ha intervenido en forma crítica y competitiva cuando se ha sentido invadida en su terreno.

Las grandes preguntas kantianas se refieren a las facultades y límites del hombre. En su radical pregunta ¿qué es el hombre? confluyen los intereses de la razón, que Kant plasmó en sus tres conocidos interrogantes: resumía la metafísica (¿qué puedo saber?), la moral (¿qué debo hacer?) y la religión (¿qué puedo esperar?) (Kant 1996, 630). Mientras que el sentimiento religioso del hombre concreto fue el centro del pensamiento de Schleiermacher, ya que, ni la razón ni el pensamiento ni los evangelios ni la Iglesia conducían a Dios, sino sólo el hombre en su sensibilidad, emociones y sentimiento, es decir, la piedad, la devoción sentida y la mística. La religión no pretendía explicar el universo, sino contemplarlo y empaparse de él; lo importante era la admiración, el sobrecogimiento.

Desde el punto de vista historiográfico, la primera obra que estudió el surgir de la filosofía de la religión fue escrita por el filósofo kantiano Immanuel Berger, y se publicó en Berlín en 1800 con el título: Geschichte der Religionsphilosophie oder Lehren und Lehrmeinungen der originellsten Denker aller Zeiten über Gott und Religion historisch dargestellt (Feiereis, 1965). Es interesante constatar que Berger equipara la filosofía de la religión con la historia de una reflexión libre sobre la religión. Mientras la religión fue, desde un punto de vista sociopolítico, algo dado, evidente y obligatorio, la misma religión se ocupó de sofocar todo pensamiento libre y autónomo sobre ella. Sólo cuando la religión fue perdiendo poder, pudo ser objetivada en un proceso reflexivo que a través de variadas y agitadas etapas culminó en la rotunda negación de los contenidos religiosos llevada a cabo por el ateísmo contemporáneo. Pero, para llegar a la radicalidad de este estadio, hubo que esperar a los siglos XIX y XX (Fraijó, 2010, 21).

\section{Immanuel Kant: Cuestionamiento de la Metafísica tradicional}

Immanuel Kant en el año 1781 publica su libro capital Kritik der reinen Vernunft. Justamente la palabra "crítica" es esencial en ese periodo. Lo interesante es que en sus obras de madurez, ya más propiamente personales, que marcan un estilo nuevo, él tiene conciencia del viraje que va a producir su filosofía y dice que se trata de "un giro copernicano". Es 
decir, él tiene perfecta conciencia de un estilo nuevo, que tiene que ver evidentemente, con la tendencia que ya se advierte claramente en Descartes: la tendencia a evitar el error, más que el descubrimiento de la verdad. La primera pregunta que se nos plantea es, ¿cómo evitar el error en campos como la filosofía y la religión, donde su mismo objeto de estudio es el "Todo del Universo"?

Por ello Kant va a ir paso a paso desgranando el conocimiento humano, y así en la Crítica de la Razón Pura, dice:

el conocimiento humano comienza con intuiciones, pasa a los concepto y concluye con las ideas" (B730). La unidad sistemática del saber no es una unidad dada, sino proyectada (B 675). La noción de una inteligencia extramundana tiene un carácter obligado para dar sentido objetivo final e integrado al conocimiento de la razón teórica y hace concebir la naturaleza como dotada de una unidad y un orden por obra de aquél (B725).

En el marco del uso teórico de la razón, Dios nos es dado, según el pensamiento kantiano, como un ideal trascendental, es decir, como un concepto de la razón pura teórico-especulativa, como un polo o principio regulativo hacia el cual avanza el conocimiento humano. La Idea por contener lo incondicionado (la totalidad de las condiciones de lo condicionado dado) sobrepasa el ámbito de toda experiencia posible, por lo que nunca podremos encontrar en la experiencia algo que le corresponda (lo perfecto o lo completo de una clase de cosa). En la Idea de Dios esta perfección puede ser tomada en dos sentidos, es decir, en un sentido teórico como ens summum, Dios (modelo de todo ente en cuanto tal), y en un sentido práctico como perfectio moralis (a lo que debería tender todo ente por obra de la libertad). Si bien, por medio de los conceptos trascendentales, según Kant, no se puede determinar ningún objeto, sin embargo, puede ser considerado imperceptiblemente, como el canon y la guía en el uso del entendimiento ( $K r V$ A 329 B 385).

En Kant la teología es concebida como el sistema de nuestros conocimientos acerca del Ser Supremo. El conocimiento de todo lo que tiene lugar en Dios es lo que Kant llama, theologia archetype y éste solo tiene lugar en Él, mientras que el sistema de los conocimientos de aquello que de Dios reside en la naturaleza humana se llama theologia ectypa, y puede ser muy deficiente. La totalidad de todo conocimiento posible acerca de Dios no es posible para el hombre. Sin embargo es la consideración más digna del hombre el ver hasta dónde puede llegar nuestra razón en el conocimiento de Dios. Para Kant no hay más teología que la de la razón o la de la revelación. La teología de la razón es o bien especulativa, basada en un saber teorético, o bien moral, que tiene el conocimiento práctico como objeto; pero para ser precisos, dice Kant, dividimos la teología racional en a) trascendentalis, b) naturalis y c) moralis. La primera consiste en pensar a Dios sólo por conceptos trascendentales, es decir, se piensa a Dios como ens originarium, como ens summum, lo cual supone que el Ser Originario no proviene de otro ser y es raíz de toda posibilidad. En la segunda se piensa a Dios por medio de conceptos físicos, como Autor de todos los seres posibles, es decir, como ens origunarium, como summa intelligentia, o también Dios como ser vivo quien debe haber empleado su entendimiento y voluntad libre para la producción del mundo. En tercer lugar se piensa a Dios como ens originarium, como summum bonum, es decir, como el Sumo Bien 
o supremo fundamento del conocimiento como un sistema de todos los fines. En la teología trascendental nos representamos a Dios como Causa del mundo, en la teología natural, como Autor del mundo, y por último en la teología moral, como Soberano y Legislador.

En el theismus moralis, se piensa a Dios como autor de nuestras leyes morales, y ésta, según Kant, es la auténtica teología que sirve de fundamento de la religión. Kant distingue entre moral teológica, donde las obligaciones morales presuponen el concepto de Dios que determina todos los deberes, y teísmo moral que concibe a Dios no como primer principio de la Naturaleza sino como principio del Reino de los Fines; la creencia de que Dios existe se infiere a priori de los principios morales, y con esto se deja libre el paso para las pruebas prácticas como principio de todas las religiones. El teísmo moral kantiano es crítico, declara insuficientes a las pruebas especulativas de la existencia de Dios, pues considera imposible demostrar la existencia de modo apodícticamente cierto, pero está convencido de la existencia de Dios y tiene una fe libre de toda duda en el fundamento práctico que nunca podrá ser derribado, pues los hombres se desbaratan al chocar con ello. Esta moralidad absolutamente necesaria de las acciones emana de la idea de un ser racional que obra libremente y de la naturaleza de sus propias acciones no hay nada más cierto ni más firme que la obligación de actuar moralmente bien. Las acciones se rigen todas y están determinadas por su naturaleza para el hombre (quien es tal cuando pone en ellas sus propios fines). El hombre cuando es consciente de cumplirlas, se sabe cómo un eslabón en la cadena de todos los fines, digno de felicidad con la esperanza de constituir con los otros un todo en el Reino de la moralidad.

Del planteamiento kantiano se desprende que el hombre tiene en la moralidad el fundamento seguro sobre el cual poder edificar su fe en (el) Dios (cristiano), porque siente en sí el impulso a esperar la felicidad duradera, cuando actúa conforme a deberes fundados en su propia naturaleza. Por su propia razón estará obligado a pensar un Ser cuya Voluntad son los mandamientos que el hombre conoce dados a priori por sí y de un modo apodícticamente ciertos. Tendrá que pensar en un tal ser como Perfecto (con respecto a todo), como Omnisciente (con respecto a los motivos y propósitos), Omnipotente (con respecto al orden de la naturaleza), Santo y Justo. El teísmo moral, se hace un concepto determinado de Dios conforme a la moralidad, es decir, a las leyes fundadas en su propia naturaleza racional. Así se deduce la teología de la moral, según una evidencia práctica, no por el saber, sino por la fe. Por ello, la existencia de un sabio gobernante del mundo es un postulado necesario de la razón práctica. El concepto de Dios es posible cuando no contradice las leyes del entendimiento. La posibilidad de este conocimiento de Dios está basada en la moralidad. Esto es suficiente para generar la religión en el hombre, pero no es el máximo de la teología. Lo mejor es que además sepa que un ser tal efectivamente existe. Para Kant todo conocimiento tiene dignidad en tanto guarde relación con la religión; pues la religión no es más que la aplicación de la teología a la vida práctica, esto es, a las buenas intenciones y a un comportamiento grato al Ser Supremo. La religión natural es el substrato de toda religión, el sostén y la firmeza de todo principio moral, y la teología natural, especie de teología racional, que intenta determinar la existencia y la naturaleza de un Autor del mundo sobre la base de una "analogía con la Naturaleza" ya sea según la naturaleza de nuestra alma o la del mundo ( $K r V$, A 631-632/ B659-660), posee un valor que la eleva por encima de toda especulación, en tanto es hipótesis de toda religión y le proporciona el peso a todo concepto de virtud y honradez. 
Kant, en La Religión dentro de los límites de la razón (1793), expone: "La Religión es el reconocimiento de todos nuestros deberes como mandatos divinos" (Kant, 2001, 153). A partir de una posible unidad de la teología filosófica y la teología revelada, en virtud de una supuesta coincidencia entre la revelación y la razón pura, Kant nos proporciona una interpretación moral de las afirmaciones bíblicas que refieren a la naturaleza humana dotada de disposiciones buenas y malas. La religión cristiana es, según Kant, una religión natural en cuanto Moral (en relación a la libertad del sujeto) ligada a un fin último (Dios como autor moral del mundo) referida a la duración del hombre de acuerdo a ese fin (inmortalidad) a la que "los hombres pueden y deben llegar por medio de la razón práctica pura" (Kant, 2001, 153). Pero la religión cristiana también es una religión erudita, según su contenido y los principios que se encuentran dentro de ella, y, en cuanto tal, expone la tesis de la fe que no puede ser reconocida por la razón, pero que, sin embargo, debe ser comunicada sin adulteración a todos los hombres en todos los tiempos venideros, considerado como un bien santo confiado a los eruditos. En la aceptación de sus principios, la fe cristiana (fides sacra) es por un lado pura fe racional libremente aceptada por cada uno de nosotros (fides elícita), y por otro lado fe de revelación (fides statutaria). La religión cristiana edificada sobre hechos (y no sobre meros conceptos racionales), es una fe religiosa puesta a la base de una iglesia consagrada a su fe cristiana con dos caras, por un lado, la de aquella que responde según una fe histórica, y, por el otro, la de aquella que responde según una fe racional práctica y moral (Kant, 2001, 160). En efecto "las leyes puramente morales no son únicamente la condición insoslayable de toda verdadera religión, sino que son también aquello que constituye esta misma religión" (Gómez Caffarena, 1984, págs. 179-196). Por tanto, es necesario una ilustración religiosa, mediante la cual llegamos a que el individuo respete una serie de normas apoyado únicamente en el cumplimiento del deber, y mediante esta conducta voluntaria y bien intencionada consigue el individúo cumplir la voluntad divina. Así en la ilustración religiosa, moral y religión se identifican, ya que lo que la religión racional propugna es el cumplimiento por el mero hecho del deber de las normas morales.

\section{Friedrich Daniel Ernst Schleiermacher: Cuestionamiento de la Teología tradicional}

Como hemos referido, el espíritu de la época busca refugio después de la pérdida del contenido absoluto; y mientras que Kant lo ha buscado en una "fe racional", Schleiermacher, lo buscará en el sentimiento. Su obra, salida del mundo romántico, va a intentar otro tipo de solución para el problema religioso: buscar un ámbito que se sustraiga a la crítica de la Ilustración. Ese ámbito vendría a ser el sentimiento como provincia autónoma, sede genuina de la religión. En su obra Sobre la religión (1799) afirmaba que la religión es la "percepción e intuición del Universo" y el "sentimiento del infinito en lo finito". No sometida a los dogmas, consideraba que es la raíz y el fundamento del hombre, y que juega un papel necesario en todas las culturas. Siguiendo la teoría avanzada más de mil años antes por San Agustín de Hipona, afirmaba que el conocimiento del alma es indisociable del de Dios. En su obra más importante, Der christliche Glaube (2 vols., 1830-1831, Schleiermacher, 2013), definía la religión como el sentimiento de dependencia absoluta: "dependencia del ser (entidad finita) respecto del Infinito o Dios". El pecado nace de la incapacidad para distinguir esa dependencia absoluta (respecto a Dios) de la dependencia relativa (con el mundo temporal). 
Para el estudio y análisis de la obra schleiermachiana, vamos a trabajar con la obra Über die Religion. Reden an die Gebildeten unter ihren Verächtern (Schleiermacher, 1990), aparecida en 1799, pues se trata probablemente de la obra más representativa del autor y, a la vez, de la que gozó de mayor difusión, pasando a formar parte de las obras clásicas de la filosofía de la religión, para lo cual utilizaré la obra traducida por el profesor Arsenio Ginzo, para referirme a la obra original de Schleiermacher. En ésta obra será tachado de spinozista y panteísta, y la censura eclesiástica lanzará graves acusaciones sobre la obra. No obstante, autores como Fichte, Schlegel, Schelling, Goethe y Hegel se harán eco de uno de sus escritos más polémicos, donde defiende la necesidad de una iglesia separada del estado, y una teología separada de la filosofía; y un año después, en 1800, aparecen de forma anónima sus Monologen: Eine Neujahrsgabe (Schleiermacher, 1991), donde reivindica la libertad individual y el valor del sujeto humano.

De una forma un tanto paradójica, el movimiento secularizador ilustrado incidió en el auge de la filosofía de la religión que se está produciendo en este momento. Se trata de encontrar una fórmula nueva para hacer atractiva la problemática religiosa a una época escéptica y cansada a este respecto. Los destinatarios son, no obstante, un grupo cualificado: los "Gebildete" (Schleiermacher 1990,3-4). A su manera también Schleiermacher desea "reconciliar" religión y cultura en el seno de la conciencia moderna. Schleiermacher era consciente de que su época, debido a la crítica de la Ilustración y a las tendencias que se manifestaban dentro del Idealismo alemán, era una época que se había extrañado de la religión. Frente a ello, su convicción es que todavía no se ha identificado su auténtica naturaleza y que está inédita aquella dimensión del ser humano de donde brota. Schleiermacher va entonces a intentar aquella solución que quedaba por acometer después del desgaste y erosión causados por la Ilustración: el refugio en el sentimiento. Cabría preguntarse por lo demás, si ¿el espíritu romántico con su añoranza del pasado y con sus métodos pararracionales de acceso a la realidad no mostraba precisamente una predisposición hacia una concepción religiosa de la vida? Parece que esta pregunta exige efectivamente una respuesta afirmativa. Lo que ocurre es que se trata de una religiosidad distinta de la tradicional, apareciendo más bien como una amalgama de elementos de la Antigüedad clásica, del Cristianismo y del mundo oriental, integrado todo en una visión panteizante y estetizante. Con ello se consumaba un distanciamiento frente a la tradición filosófica y teológica, que habían dominado la cultura occidental, en mayor grado de lo que los mismos románticos fueron conscientes, y esto parece haberle ocurrido también a Schleiermacher. De un modo similar a Hegel, también Schleiermacher declara que el hombre moderno se encuentra tan absorbido por su mundo que ya no encuentra lugar para la Divinidad.

Así como quedan abandonados los templos exteriores dedicados a la misma, así también el corazón del hombre se encuentra atosigado por los nuevos motivos de la experiencia de su situación en el mundo, no quedan más dioses domésticos que las sentencias de los sabios y los cánticos de los poetas. (Schleiermacher 1990, 3).

Los ideales de la humanidad y la patria, el arte y la ciencia que se encontraban entonces en plena eclosión absorbían de tal forma el espíritu del hombre culto contemporáneo que ya no dejaba espacio alguno para "el ser eterno y sagrado" que se encuentra más allá del 
mundo (Schleiermacher, 1990,4), reconociendo también, que el hombre moderno ha logrado transformar y adaptar la realidad terrena de un modo tan complejo y bajo tan distintas perspectivas, que ese hombre ya no siente la necesidad de remontarse a la consideración de lo eterno tal como postulaba Spinoza. Por el contrario, la experiencia demiúrgica del hombre en cuanto artífice de un universo propio, le hacen sentirse demasiado orgulloso para pensar a su vez en Aquel que le ha creado (Schleiermacher, 1990, 4).

Los destinatarios de los Discursos eran los compatriotas cultos de Schleiermacher que cultivaban afanosamente todas las facetas de la cultura humana, pero que, bajo el influjo de la crítica ilustrada, consideraban la religión como algo trasnochado por el paso de los tiempos; a lo que se añade, que esos interlocutores tienen que ser precisamente alemanes, puesto que se trata de aquel pueblo donde es posible un desarrollo armónico de las facetas humanas más profundas, asoma por tanto, una conciencia de características un tanto mesiánicas acerca de la misión del pueblo alemán, sobre todo por lo que se refiere a la dimensión filosófica y religiosa. En efecto, al igual que Hegel cree que ese pueblo "ha recibido de la naturaleza la alta vocación de ser el guardián de este fuego sagrado" (Schleiermacher, 1990, 4). Por tanto los destinatarios de sus Discursos de Schleiermacher conocen los avatares por los que ha pasado la problemática tratada, en los últimos tiempos; por eso no va a repetir, una vez más, lo que ya es de sobra sabido. Dejando a un lado todas las actitudes que le parecen insatisfactorias, Schleiermacher quiere avanzar hasta las

profundidades más íntimas del espíritu humano, allí donde brotan los sentimientos más originarios del alma y mostrar cómo el sentimiento religioso brota de esos estratos más profundos de la humanidad y pertenecen, por ello, a lo más elevado y querido que ésta tiene" (Schleiermacher, 1990, 15).

Schleiermacher quiere en primer lugar evitar los equívocos con que nos tropezamos en la historia de la religión desde las "fábulas absurdas de los pueblos salvajes hasta el más refinado deísmo, desde la superstición más primitiva hasta aquella especie de cristianismo racional, producto de la Ilustración, que viene a ser un conglomerado bastante heterogéneo de metafísica y moral" (Schleiermacher, 1990, 18). Los dos conceptos frente a los que va a tratar de edificar su propio concepto de religión. A lo largo del devenir histórico asistiríamos a un refinamiento creciente en esa combinación de metafísica y moral. Situados en esta perspectiva llegaríamos al deísmo del siglo XVIII, producto artificioso de la época ilustrada (Ginzo, 1994).

Ante esta situación es preciso realizar un viraje. A los ojos de Schleiermacher, los críticos de la religión no pudieron encontrarla en los sistemas mencionados y ello por la sencilla razón de que la religión no se encontraba allí. ¿Dónde se encontraba pues? En los estratos más profundos del espíritu humano. La religión, afirma más explícitamente Schleiermacher, "brota necesariamente del interior de cada espíritu noble, de modo que le pertenece una "propia provincia" en el espíritu humano, dentro del cual reina sin obstáculos de tal manera que es digna de ser conocida y apreciada por sí misma (Schleiermacher, 1990, 25-26).

De lo expresado hasta ahora, ya han asomado dos características fundamentales del pensamiento religioso schleiermachiano: predominio del aspecto subjetivo en el concepto de religión y la valoración de dicho concepto en polémica contra la Ilustración y el Idea- 
lismo alemán. Pero ocurre que la religión ve desfigurada su propia naturaleza a lo largo de la historia debido al hecho de que "tiene un mismo objeto con la metafísica y la moral, a saber, el Universo y la relación del hombre con él" (Schleiermacher, 1990, 29). Por tanto, ve en esta igualdad de objeto el origen de muchos equívocos sobre el tema que está tratando. Aparecen utilizados aquí los términos de "metafísica" y "moral" sin mayor rigor. Pero, por el contexto, está claro que Schleiermacher piensa sobre todo en la metafísica de la Ilustración y en los sistemas morales de Kant y Fichte. Ante tal situación, Schleiermacher puede afirmar que la metafísica y la moral han invadido el campo de la religión y: "mucho de lo que pertenece a la religión se halla encubierto de un modo indebido en la metafísica o en la moral" (Schleiermacher, 1990, 29). Por lo tanto, su lucha va a consistir en ganar un "espacio" para lo religioso, que vendría a ser la condición primordial, el nivel más originario del espíritu humano. El problema, entonces, consistirá en deslindar una metafísica teologizante concebida como ontoteología, o una moral, asimismo de corte teológico, de la religión misma para poder garantizarle a esta última, una "provincia" propia que la mantenga incólume a pesar del proceso de secularización emprendido por el mundo moderno.

Para localizar esta propia provincia, Schleiermacher quiere adelantarse al proceso de descomposición de la metafísica racionalista de la Ilustración ${ }^{2}$ (deísmo) o situarse más allá de los sistemas morales de los grandes idealistas contemporáneos suyos en los que la moral parecía absorber realmente a la religión. Ante la perplejidad de la situación que está viviendo, lo que pretende es elaborar un concepto "químicamente puro" de la religión. Dicho concepto seria el principio último de unidad del mundo espiritual del hombre. Dicha unidad sólo es posible, de una forma coherente, si se admite a la religión como principio supremo unitario. "La religión sería lo supremo en filosofía, y la metafísica y la moral serán formas subordinadas de la misma" (Schleiermacher, 1990, 31).

Pero ¿en qué consiste la religión en cuanto independiente de la metafísica y la moral? En un conocido pasaje de los Discursos, Schleiermacher la describe así:

(la religión) no pretende, como la metafísica, determinar y explicar el Universo de acuerdo con su naturaleza; tampoco pretende como la moral transformar y hacer disponible dicho Universo partiendo de la fuerza de la libertad y del albedrío divino del hombre. Su esencia no consiste ni en pensar ni en obrar sino en la intuición y en el sentimiento. Lo que ella pretende es contemplar el universo, quiere venerarlo piadosamente en sus representaciones y acciones, quiere dejarse impresionar y plenificar en la ingenua pasividad por los influjos inmediatos del mismo. (Schleiermacher, 1990, 35).

El término intuición tiene, como es obvio, una connotación más objetiva que el sentimiento; sería, en este sentido, un aspecto de la religión que la vincula con el objetivismo de la ciencia. Por eso el término "sentimiento" tiende a suplantar al término "intuición". Schleiermacher se adentra en su proceso de subjetivización de la religión declarando, a la

2 "Por lo que se refiere a la metafísica, la marcha negativa que hasta la fecha ha seguido hace dudar a todo el mundo, con razón, de su posibilidad. Esto por una parte; por otra, ninguna de las formas adoptadas hasta hoy por la metafísica permite afirmar, que lo que a su objetivo esencial atañe, que exista realmente.”( KrV B 21). 
vez, que quiere reaccionar frente a los equívocos de su tiempo, sobre todo en lo referente a las relaciones entre religión y filosofía. Se trataría de hacer resaltar lo máximo posible el carácter específico del hecho religioso concibiéndolo como "sentimiento de absoluta dependencia” (Schleiermacher, 1990, 49-50). Dependencia ¿de qué o de quién? Schleiermacher utiliza distintos términos: el Universo, lo Infinito, el Todo... prefiere utilizar estos términos al de Dios $^{3}$. Todo ello indicaba claramente un viraje en el modo de concebir la Divinidad. Nos movemos en una visión del mundo fundamentalmente panteísta. Mientras que Dios era el ens realissimum dentro de la visión teísta, ahora se prefiere evitar este nombre porque, al fin y al cabo, en el nuevo marco de comprensión de la esencia de la Divinidad, parecía que el nombre de Dios no designaba más que un ser privilegiado, pero no el Todo de la realidad. El caso es que Schleiermacher cree haber encontrado esta tercera faceta "necesaria e imprescindible" junto con la especulación y la praxis. Vemos que junto con el término "especulación" aparece citado asimismo el término "praxis", y así como la religión se sitúa en un plano más originario y subjetivo que la especulación, así también tiende a desvincularse de la praxis, al caracterizar el sentimiento religioso como dominado por la pasividad ante el Universo. Por eso, la religiosidad de Schleiermacher aparece dominada más bien por el amor dei intellectualis de raigambre spinozista. Una mística cósmica que experimenta ahora en el romanticismo un segundo momento de esplendor después del que había tenido lugar en ciertos pensadores del Renacimiento. Respecto a Spinoza nos dice expresamente que

lo infinito era su comienzo y su fin, el Universo, su único y eterno amor... Se encontraba lleno de religión y lleno de espíritu santo, y que por ello también se presenta, sólo e inigualado, como maestro en su arte... (Schleiermacher, 1990, 37-38).

Ese concepto de religión basado en el puro sentimiento va a hacer posible, desde una nueva perspectiva, el clima de tolerancia de tanta incidencia en el pensamiento de la Ilustración. De un modo similar a como, por ejemplo, Lessing defendía un punto de vista relativista respecto al ámbito religioso, también ahora Schleiermacher va a hacer lo mismo apoyándose en la vaciedad del sentimiento: "lo fundamental es el sentimiento de dependencia del Universo de modo que las distintas formas religiosas no son más que concreciones de este sentimiento fundamental" (Schleiermacher, 1990, 44). Se trataría de un ecumenismo religioso basado en el sentimiento. Dado el carácter subjetivo del mismo, cada uno lo experimentará de una forma distinta, por más que en todo ello habría una coincidencia fundamental, precisamente en el sentimiento de dependencia del Universo. Sin embargo, Schleiermacher logra superar en parte el individualismo atomizante al que apuntaba su subjetivismo religioso en la medida en que en su pensamiento está pesando visiblemente el concepto de Humanidad que, de un modo particular desde la Ilustración, venia perfilándose dentro del pensamiento occidental, pasando a través de pensadores como Kant, Herder, Goethe... Lo que ocurre es que esa comunión entre todos los individuos que constituyen el género humano tendría un sentido más bien místico que racional. Para Schleiermacher lo Absoluto sería algo que tan sólo es accesible a la fe o al sentimiento, pero no a la "razón cognoscente", propuesta por

3 Los intérpretes de Schleiermacher han llamado frecuentemente la atención sobre este punto. Véase, por ejemplo, la exposición de R. Otto en la edición de los Discursos. 
Kant. La consecuencia de ese proceso de subjetivización va a ser precisamente que se pierde la "catolicidad de la religión" para degenerar más bien en una especie de "atomismo universal", un conjunto de átomos yuxtapuestos debido a la ausencia de una objetividad vinculante.

Expuesto su punto de vista acerca de la esencia de la religión, Schleiermacher advierte que es preciso hacer una serie de matizaciones respecto al pensamiento tradicional. Se trata ante todo del valor del "contenido" de las distintas formas religiosas. Para Schleiermacher no tendría más que un valor secundario. Dicho contenido, expresado de un modo conceptual, no es más que una elaboración abstracta de aquel sentimiento básico que está en la base de la religión. Cada uno lleva en su propio interior, lo que los distintos mediadores religiosos no hacen más que contribuir socráticamente a su alumbramiento. En este sentido puede Schleiermacher hablar despectivamente de aquellos que permanecen fijados en una "Escritura muerta":

Cada Escritura sagrada es tan sólo un mausoleo, un monumento de la religión que nos atestigua que allí ha estado un gran espíritu, pero que ya no está más... No tiene religión quien cree en una Escritura sagrada, sino aquel que no necesita ninguna e incluso podría él mismo producir una. (Schleiermacher, 1990, 79-80).

Pero, dentro de todo este contexto, tiene particular interés el modo como Schleiermacher aborda el problema concreto de Dios. En realidad se trata de un problema básico dentro de la exposición schleiermachiana, pues Hegel va a señalar con razón que aquí asistimos claramente al desplazamiento del centro de interés desde Dios a la religión. En efecto, Schleiermacher va a confesar a sus interlocutores que en el seno de su concepción no es válido eso de que "sin Dios no hay religión alguna" (Schleiermacher, 1990, 81); asimismo cabe afirmar "que una religión sin Dios puede ser mejor que otra con Dios" (Schleiermacher, 1990, 82), puesto que Dios no sería, en definitiva más que una concreción, entre otras, del sentimiento religioso.

Sin embargo, hay que manifestar rápidamente que para Schleiermacher, Dios y el mundo están indisolublemente relacionados. Imaginar al mundo sin Dios es perder de vista el lazo de unión; imaginar a Dios sin el mundo es imaginar un concepto vacío. No obstante, Dios y el mundo no son idénticos, pues el mundo es la unidad suprema inclusiva de todas las antítesis, mientras que Dios es la unidad suprema exclusiva de todas las antítesis. Ambas ideas, por tanto, sustentan una relación distinta al conocimiento, siendo Dios el terminus a quo y el mundo el terminus ad quem.

En concreto, en lo referente a la interpretación del ámbito teológico y religioso, salta a la vista la intensidad con que Schleiermacher recurre a la psicología para exponer su punto de vista. Por otra parte, cabe considerar a Kant como un punto de referencia fundamental a la hora de entender mejor esta tendencia a la subjetivización de lo religioso, en la medida en que la ciencia queda reducida ahí al ámbito de lo fenoménico, de forma que el "mundo eterno" no es alcanzado por investigación alguna. Lo Incondicionado queda vinculado a la voluntad moral y como consecuencia de ello, también la religión queda sometida a un proceso "discursivo". Frente a esto, la voluntad de Schleiermacher habría consistido en "completar" el punto de vista kantiano acerca de los límites del conocimiento científico, en la medida en que para él todas las convicciones religiosas tienen un carácter "inmediato", "pertenecen a lo más íntimo de nuestra persona, y en ésto reside su evidencia". 


\section{Consideraciones o conclusiones}

La realidad (cósmica, natural, mundanal) aparece simultáneamente como caótica y maravillosamente ordenada, como cosmos regulado y como anarquía amenazante. El mito es la gran creación cultural, en la que se combinan los distintos saberes y se buscan respuestas al por qué y para qué del mundo y del hombre. Inicialmente no surge tanto la pregunta filosófica acerca de “¿por qué hay algo y no hay nada?”, cuanto la previa acerca del sentido (orden) y significación (valor) del universo, del que forma parte el hombre y la naturaleza 4 .

El universo religioso consta de dos polos, Dios y el hombre. La historia de las religiones muestra las oscilaciones de la relación ${ }^{5}$. Por lo tanto, en la filosofía de la religión son dos las realidades comprendidas: religión y filosofía. Esa vinculación abre la posibilidad de elegir el punto de partida de la filosofía de la religión, en la filosofía o en la religión. La posibilidad de situar el epicentro en una o en otra, permite abordar la problemática de forma diferente y con respuestas también diferentes. Una filosofía de la religión que centra su interés en la filosofía y hace de ésta su punto de partida, está claro que la considera anterior en el tiempo y superior en importancia, y sólo se ocupa de la religión por el hecho de que la filosofía es una ciencia universal y se pregunta por la realidad experimental en su conjunto averiguando sus condiciones de posibilidad. Aquí la filosofía se convierte en el poder que todo lo determina. Se cultiva la filosofía de la religión sobre la base de una filosofía determinada y se interpretan los fenómenos religiosos de acuerdo con un sistema filosófico previo. Es la filosofía de la religión fundada por Kant (1793) y que en el neokantismo adquiere sus perfiles más precisos.

Por otro lado, el interés de la filosofía de la religión puede también situar su epicentro en la religión, dándole la primacía, eligiéndola como punto de arranque y otorgándole la vigencia que corresponde a lo que temporal y objetivamente es anterior. En efecto, la religión no debe su existencia a la filosofía; tiene su propio origen en la experiencia religiosa; en ocasiones se vive con intensidad, aun sin ir acompañada de una filosofía explícita. Por tal motivo algunos filósofos consideran adecuado empezar por el conocimiento de cómo las personas religiosas se entienden a sí mismas en su lenguaje y comportamiento religiosos y, respectivamente, de cuáles son las afirmaciones que las religiones hacen de sí mismas y cuáles son sus pretensiones y exigencias. Tal concepto de una filosofía de la religión sólo podía surgir tras haber sido superada la concentración del pensamiento filosófico moderno en la conciencia y su función mediante un giro hacia el objeto, que hoy aparece claramente en la consigna del movimiento filosófico de la fenomenología, ligada al nombre de Husserl: “ Vuelta a las cosas!" El pensamiento lucha por liberarse de todas las opiniones tradicionales y preconcebidas sobre los objetos, así como de las tendencias de todo tipo hacia construcciones aprioristas, al tiempo que procura volverse a las cosas en actitud de entrega ingenua intentando estudiarlas en su realidad dada. Este tipo de filosofía de la religión, que pretende entender la religión y su importancia por vía de acuerdo, arranca del supuesto de que en la consideración objetiva la esencia de las manifestaciones religiosas se le aparece a quien se deja afectar por las mismas y está persuadido de que toda visión que se presenta como originaria es una fuente legítima de conocimiento. Dicho concepto de una filosofía de la religión

4 El significado de los mitos en relación con la filosofía, la religión y la ciencia en Estrada, 1994, 29-48.

5 Para ampliar este tema ver Eliade (1988). 
resulta más adecuado a la autonomía y pretensión de la religión. Tampoco corre tanto el peligro de someter la religión a una ley que no le hace justicia. La religión vivida precede a cualquier filosofar que se haga sobre la misma; la religión tiene la primacía. Un ejemplo de este tipo es la filosofía de la religión de Schleiermacher, montada sobre el conocimiento básico de la autonomía de la religión, que trata de la esencia y de la verdad de la religión.

Por otro lado, la crítica de la religión subraya los límites de la subjetividad humana, tanto del conocimiento como de la experiencia, y avisa del peligro de la especulación teológica, precisamente porque pretende trascender lo humano. Sin embargo, la filosofía no sólo no puede acabar con el fenómeno religioso, sino que se inspira en él. De hecho la filosofía occidental sería inexplicable sin muchas de las referencias que ha asumido de las religiones bíblicas, que son las que le han servido de fuente de inspiración, aunque, al mismo tiempo, las haya criticado e impugnado. Por eso, la filosofía y la religión han tenido una relación compleja y conflictiva, al menos en nuestra cultura occidental. La filosofía en cuanto saber reflexivo, crítico, racional e inmanente, que evalúa y analiza los otros saberes humanos, ha interpelado y, frecuentemente, descalificado la validez del saber religioso y las funciones ejercidas por la religión. La fe no es algo puntual, aunque una experiencia concreta puede ser decisiva en la vida de una persona, sino que se inscribe en el entramado biográfico y procesual de cada uno de nosotros. En realidad tanto la creencia religiosa, como la increencia, en su versión agnóstica o atea, responden a un proceso existencial y no se reducen a la aceptación o no de una determinada prueba o justificación de la existencia de Dios ${ }^{6}$. Ante el fenómeno religioso nadie es neutral, siempre estamos remitidos a un imaginario de sentido con raíces míticas, simbólicas y afectivas, que no sólo subyacen a las religiones sino también a las cosmovisiones filosóficas. Podemos basar nuestro comportamiento en una comprensión no religiosa del hombre, en un humanismo de cuño filosófico, pero esta cosmovisión humanista es tan mítica, infundamentable y en última instancia subjetiva como la religiosa. Por eso, la respuesta de una persona religiosa al ataque de un humanista ateo, puede ser también la de "tu quoque", porque, en cuanto animal que se hace preguntas, el ser humano siempre procede desde convicciones no demostrables y certezas subjetivas.

En esta misma línea, ante el reflujo de la Ilustración y de su proyecto de desencantamiento del mundo, el Romanticismo propicia el "retorno de los dioses" y está a la búsqueda de una "nueva mitología" (Schleiermacher, 1990, 27-31), pues los Discursos surgen en el que cabe denominar período fundacional de la filosofía de la religión y, con todas las carencias y limitaciones, no deja de constituir una de las expresiones paradigmáticas de esta disciplina. En el caso del cristianismo la implicación de la razón en la religión fue más fuerte que en otros contextos culturales, porque los cristianos se presentaron en la sociedad romana como representantes de la verdadera filosofía ante una cultura marcada por el logos de la cultura griega (Cicerón 2007). De ahí, la necesidad de la teología y la filosofía de la religión, que clarifican los presupuestos filosóficos de los mismos pronunciamientos religiosos, así como también la crítica teológica de las distintas escuelas filosóficas, que han servido de inspiración a la misma filosofía ${ }^{7}$.

6 El significado limitado de las pruebas de la existencia de Dios y la importancia de la biografía personal, desde donde creemos o no en Dios, ha sido el objeto de estudio en Estrada, 1996, 257-280.

7 Así lo reconoce J. Habermas, 1990 y 2002, 141-144. 
Schleiermacher supone una clara revisión de los planteamientos kantianos. Hace una construcción filosófica en la que intenta recuperar una cierta importancia para el tema de la libertad, a la que considera como el bien más originario y primitivo. Uno ha de mirarse a sí mismo y entonces: “¡Libertad! (...), en cuanto vuelvo sobre mí mismo para contemplarme, entonces mi mirada se aleja de la esfera del tiempo, libre de los límites de la necesidad" (Schleiermacher, 1991, 19). En este proceso de autorreconocimiento, el sujeto se da cuenta de que la razón del ser del propio cuerpo, no es otra sino el espíritu. No obstante, no ve Schleiermacher esta acción como algo circunscribible únicamente al sujeto -ya que ha sido criticado su concepción religiosa como demasiado subjetivista y sentimental-, la eticidad no ha de reducirse al ámbito de la voluntad singular (a través de los conceptos), sino que su realización se emplaza en una conexión social entre varios individuos, condición ésta que Schleiermacher ve como imprescindible para la realización de lo ético. Es un modo de colectivización en el que Schleiermacher ya consigue sobrepasar el racionalismo clásico, prestando especial atención a la relación "hablantedialogante" (Schleiermacher, 1977, 329), internándose en la reflexión de Herder acerca del lenguaje. El "tú" consigue realizarse en esta acción que se da, sobre todo, gracias a la libertad.

Por otro lado, la esencia de la religión, Schleiermacher nos dirá en su "soliloquio" que es como una introspección en la autoconciencia cristiana: "Tantas veces como vuelvo mi mirada hacia adentro de mi ser más íntimo estoy en el campo de la eternidad" (Schleiermacher, 1991, 72). Ello condujo a que desde Schleiermacher, exista en el seno del protestantismo, un movimiento investigador de los fundamentos teológicos. Kant ya había dado antes una solución negativa al problema de la esencia de la religión "me vi obligado a eliminar la ciencia para levantar la fe" ( $K r V$. B XXX). Por lo que, puesto todo del lado de la fe, desbancada radicalmente la ciencia, se centraba ahora todo el interés en desentrañar la esencia y contenido de aquella fe; siendo en este punto, donde se inserta Schleiermacher. Por tanto, nos dice que en el acto de la autoconciencia, yo aprehendo mi ser radicado en el ser divino y lo aprehendo como sentimiento de dependencia absoluta. Así, el Dios de Spinoza y la "cosa en si" de Kant, no son ya objeto de razón, sino del sentimiento místico, de la religión, cuya esencia consiste en advertir lo finito ligado indisolublemente al Absoluto del que depende. Él mismo resume el debate de modo típicamente cristiano.

En la conciencia de la redención tenemos directamente el sentido del amor divino; y puesto que esta conciencia es la base de toda nuestra conciencia de Dios, su amor viene a representar para nosotros su esencia. (Schleiermacher, 1991, 96).

Como consecuencia de lo expuesto para Schleiermacher la fe no se sustenta en un saber teórico sobre el mundo y Dios; en ello, está Kant.

Pero la fe no constituye un código ético ni puede reducirse simplemente a la moral, apartándose de Kant. La fe es algo único, elemental e irresoluble, es un puro sentimiento, el sentimiento de absoluta dependencia respecto del todo. Intuición y sentimiento del universo, eso es la religión. (Hirschberger, 1978, vol. 2, 252).

De ahí, que Schleiermacher cuestionara la doctrina de los postulados en el marco de la razón práctica kantiana, lo cual va a tener a la vez consecuencias importantes para la 
filosofía de la religión, en la medida en que la crítica schleiermachiana cuestiona el último apoyo de una teología filosófica en el sentido de la metafísica tradicional (Meckenstock 1988, 154; Ginzo 1990). Por lo demás, Schleiermacher ha tratado de aplicar en su teoría ética una idea tan central en su pensamiento como es la de individualidad. Pero, a diferencia de otros románticos, se va a mostrar sensible a la vez a la inserción de los individuos en las estructuras comunitarias, desde la familia hasta el Estado. Trata de esta manera de ser fiel al doble imperativo de individualidad y universalidad.

Esta forma de entender la religiosidad por Schleiermacher, han sido decididamente combatida, dado su carácter sentimental y estético, por la religión católica -aunque no solo por ella-, que bajo el influjo de Schleiermacher, desembocó en las diversas formas del modernismo. El catolicismo reconoce también que la fe no se agota, en un puro concepto y pura racionalidad. Pero abriga el temor de que una fe que no contenga por ninguna parte elementos cognoscitivos, y particularmente no encuentre un fundamento racional en los preambula fidei, deje, de ser una fe racional y razonable (rationabile obsequium), y se quede en pura fe ciega, algo indefinible y vago, una suerte de ájeıov, como dirían los griegos.

Por ello, no todas las cosmovisiones son igualmente razonables, ni creíbles ni pertinentes, sobre todo en culturas como la nuestra que están marcadas por la racionalidad experimental científica y la reflexión crítica de la filosofía. En la religión no hay certezas sobre Dios, sino convicciones de fe. Nunca podemos demostrar que hemos llegado a lo último o a lo Absoluto, caso de que exista, y siempre hay que relativizar las representaciones que el hombre hace de ese presunto Absoluto, al que llamamos Dios. Todos los lenguajes sobre Dios son construcciones humanas, $\mathrm{y}$, en última instancia, hay que cuestionar su verdad y pertinencia, debido a que siempre estamos mediados socioculturalmente. Por eso la distinción entre la búsqueda de la divinidad y ésta misma, implica una relativización de todas las religiones, sin que esto quiera decir que todas sean iguales. Por ello creemos, que cuanta más capacidad posee una religión para dar cabida en su seno a los logros de la filosofía, menos permeable será a la tentación fundamentalista. Es, por ejemplo, la gran ventaja del cristianismo frente al islam. Lo mismo vale de la teología, donde los proyectos teológicos actuales más valiosos son los que más se han abierto a la herencia filosófica. La historia parece mostrar que ni la religión ni la filosofía salen perdiendo cuando aúnan esfuerzos, siendo precisamente esta cuestión, lo que intenta la filosofía de la religión.

Podríamos concluir, diciendo que como Kant desmontó el edificio de la antigua metafísica, así Schleiermacher, es conocido como el padre de la teología moderna, ya que destruyó la escolástica teológica. Los Discursos sobre la religión (1799) se realizaron desde la óptica de la teología protestante, bien sea desde un talante aprobatorio o polémico. Pensamos, que tiene razón R. Otto cuando señala que el interés fundamental de los Discursos es el relativo a la filosofía de la religión, en la medida en que se propone fundamentalmente investigar de nuevo la "esencia" de esta última. "Como hombre os hablo de los sagrados misterios de la humanidad", precisa Schleiermacher en el primer "discurso" (Schleiermacher 1990, 5). Así como Kant trató de obviar tanto el dogmatismo como el escepticismo, así Schleiermacher trató de hacer otro tanto frente al racionalismo y al supranaturalismo, intentado conectar, por el contrario, con los nuevos horizontes y perspectivas que ofrecía la época. Como señala Hans Küng, la mayor preocupación de Schleiermacher fue el desarrollo de una fe personal y la relación con Dios que no estaba 
obligado por el dogma y es para el desarrollo de esta filosofía que se concede el estatuto del padre de la teología moderna (Küng, 1995, 153-157). También hay que decir, que su redefinición de la teología cristiana, ejerció su impacto más fuerte en el tema de la autoridad; ya que según él, ninguna autoridad, ya sea de la Biblia, de los credos o de la Iglesia, debe prevalecer sobre la experiencia inmediata de los creyentes, frente a otras culturas, donde aún persisten la unión entre Iglesia y Estado; y donde la interpretación de las sagradas escrituras, está cerrada a una minoría o casta sacerdotal.

\section{Bibliografía}

Cicerón, M. T. (2007): Sobre la República. Sobre la naturaleza de los dioses. Trad. Álvaro D’ors y Ángel Escobar. Madrid: Gredos.

De Wulf, M. (1918): Elementos de Historia de la filosofía, Barcelona: Ed. Luis Gili.

Eliade, M. (1988): Historia de las creencias y las ideas religiosas. 3 vols. Trad. de Jesús Valiente Malla. Barcelona: Paidós.

Estrada, J. A. (1994): Dios en las tradiciones filosóficas I: aporías y problemas de la teología natural, Madrid: Trotta.

Estrada, J. A. (1996): Dios en las tradiciones filosóficas II: de la muerte de Dios a la crisis del sujeto, Madrid: Trotta.

Feiereis, K. (1965): Die Umprägung der natürlichen Theologie in Religionphilosophie, Lepzig.

Fraijó, M. (Coord.) (1996): Filosofía de la Religión, Trotta: Madrid.

Fraijó, M. (1996): "Filosofía de la religión: una azarosa búsqueda de identidad", en Fraijó, M. (Coord.) (1996), pp. 13-46.

Ferrater Mora, José. (1990): Diccionario de Filosofía, 4 vols. Madrid: Alianza.

Ginzo, A. (1981): "Estudio introductorio", en Hegel, G.W.F.: El concepto de religión, México-Madrid-Buenos Aires: F.C.E.

Ginzo, A. (1990): "Estudio preliminar", en Schleiermacher, F. D. E.: Sobre la religión, Madrid: Tecnos, pp. 9-97.

Ginzo A.: (1994) “Schleiermacher: la autonomía e inmediatez de la religión”, en Fraijó, M. (1994), pp. 239-264.

Ginzo, A. (1981): "La filosofía de la religión en Hegel y Schleiermacher", en Anales del Seminario de Metafísica, 16, Universidad Complutense de Madrid, pp. 89-118.

Gómez Caffarena, J. (1983): El teísmo moral de Kant, Madrid: Cristiandad.

Gómez Caffarena, J. (1994): "La filosofía de la religión de I. Kant”, en Fraijó, M. (1994), pp. 179-200.

Habermas, J. (1990): Pensamiento postmetafísico. Madrid: Taurus.

Habermas, J. (2002): El futuro de la naturaleza humana, Barcelona.

Hartman,N.(1960):La Filosofía del idealismo alemán. Fichte, Schelling y los románticos. Trad. de Hernán Zucchi. Buenos Aires: Sudamericana.

Hegel, G.W.F. (1966): Vorlesungen über, die Philosophie der Religion. Hamburgo: F. Meiner. Hegel, G.W.F. (1995): Lecciones sobre la Historia de la Filosofía. México: FCE.

Heidegger, M. (2010): "La época de la imagen del mundo", en Caminos de Bosque, , Madrid: Alianza, pp. 63-79. 
Hirschberger, J. (1978): Historia de la Filosofía. 2 vols. Trad. Luis Martínez Gómez. Barcelona: Herder.

Kant, I. (1996): Crítica de la Razón Pura. Trad. Pedro Ribas. Madrid: Ed. Alfaguara.

Kant, I. (2004): ¿Qué es Ilustración? Trad. de Roberto Rodríguez. Madrid: Alianza.

Kant, I. (2001): La religión dentro de los límites de la mera razón, Madrid: Alianza.

Küng, H. (2005) En Busca de Nuestras Huellas. Trad. de Carmen Gauger. Barcelona: Debolsillo.

Küng, H. (1995) Grandes pensadores cristianos. Una pequeña introducción a la Teología. Trad. Carmen Gauger. Madrid: Trotta.

Meckenstock, G. (1988): Deterministische Ethik und Kritische Theologie. Die Auseinandersetzung des frühen Schleiermacher mit Kant und Spinoza 1789-1794. Berlin/New York, 1988.

Oelmüller, W. (1979): Die unbefriedigte Aufklärung. Beiträge zu einer Theorie der Moderne von Lessing, Kant und Hegel, Francfort a Main: Suhrkamp.

Otto, R. (1985): Lo Santo. Lo racional y lo irracional en la idea de Dios. Trad. de Fernando Vela. Madrid: Alianza.

Popper, K. (1983): Conjeturas y refutaciones, Barcelona: Paidós.

Schleiermacher, F. (1977): "Über den Begriff der Hermeneutik mit Bezug auf F. A. Wolf Andeutungen und Asts Lehrbuch” in: Hermeneutik und Kritik. Frankfurt am Main: Suhrkamp.

Schleiermacher, F. (1990) Sobre la religión. Trad. de Arsenio Ginzo, Madrid: Tecnos.

Schleiermacher, F. (1991): Monólogos, Edición bilingüe hispano-alemana de Anna Poca. Barcelona: Anthropos.

Schleiermacher, F. (2013): Compendio de la fe cristiana según los principios de la Iglesia evangélica. Trad. de Constantino Ruiz-Garrido, Salamanca: Sígueme.

Wittgenstein, L. (2007): Tractatus Logico-Philosophicus. Trad. de Jacobo Muñoz e Isidoro Reguera. Madrid: Alianza. 